\title{
Ruptured Aneurysm of the Medial Posterior Choroidal Artery First Demonstrated by the Microcatheter Technique
}

\author{
-Case Report-
}

\author{
Takashi OHTA, Hitoshi OzAwA, Tatsuya YAMAUCHI, and Takamichi KUBOKURA
}

Department of Neurosurgery, Ushioda General Hospital, Yokohama, Kanagawa

\begin{abstract}
A 50-year-old previously healthy woman presented with symptoms of subarachnoid hemorrhage. Initial cerebral angiography did not determine the site of the hemorrhage but repeat angiography disclosed an aneurysm-like image, probably in the medial posterior choroidal artery (PChA). Selective angiography performed using a microcatheter technique clearly revealed two medial PChAs arising from the ambient segment of the posterior cerebral artery. One medial PChA included an aneurysm on the cisternal segment, then ran peripherally to supply the plexus in the roof of the third ventricle. The other medial PChA mainly supplied the pineal body, tegmentum of the midbrain, and posterior border of the thalamus. The patient underwent open surgery following the zygomatic approach and the parent artery was clipped. She was discharged without neurological deficits or compromise of higher brain functions.
\end{abstract}

Key words: medial posterior choroidal artery, subarachnoid hemorrhage, microcatheter, dissecting aneurysm

\section{Introduction}

Aneurysm of the medial or lateral posterior choroidal artery (PChA) is exceptionally rare. Only 10 cases of lateral PChA aneurysms ${ }^{2,3,5,8,9,11,12)}$ and only one of medial PChA aneurysm ${ }^{4)}$ have been reported, eight associated with moyamoya disease $^{2-5,9,11)}$ and one with arteriovenous malformation. ${ }^{8)}$

We describe a case of ruptured aneurysm of the cisternal segment of the medial PChA not associated with anterior circulation occlusive disease or arteriovenous malformation.

\section{Case Report}

A 50-year-old previously healthy woman suffered sudden onset of headache on October 13, 2001. The symptoms worsened the next day and she was admitted to our hospital on October 15. On admission, her consciousness was clear and she had no obvious neurological deficit other than nuchal rigidity. Routine hematological and laboratory examinations revealed no abnormality. She had no significant family history.

Received January 10, 2003; Accepted July 2, 2003

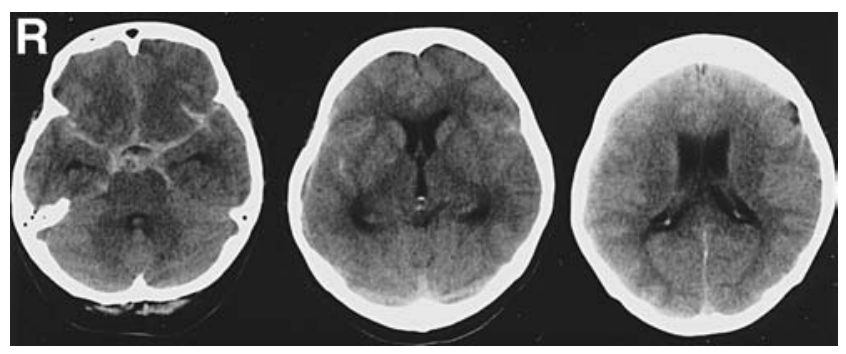

Fig. 1 Computed tomography scans on admission demonstrating subarachnoid hemorrhage in the suprasellar cistern and bilateral sylvian fissures but no hematoma in the lateral or third ventricles.

Initial computed tomography (CT) revealed subarachnoid hemorrhage (Fig. 1). Four-vessel angiography on Day 2 revealed no aneurysm other than an infundibular dilatation of the right internal carotid-posterior communicating artery (IC-PComA) bifurcation.

The patient underwent surgery following the right pterional approach under full informed consent, but no site of rupture was found in the operative field. Left carotid angiography on Day 7 demonstrated an aneurysm-like shadow filled via the left PComA 




Fig. 2 Left carotid angiogram on Day 7 showing an aneurysm-like shadow (arrow) filled via the posterior communicating artery.

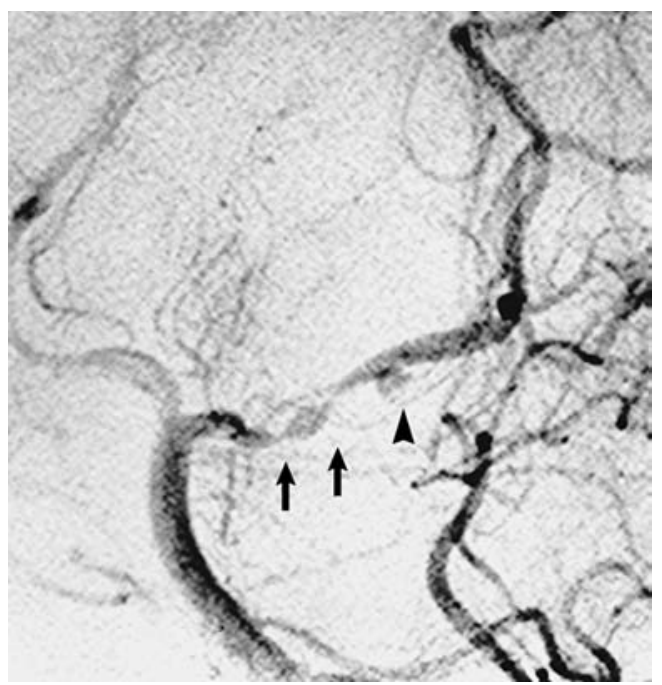

Fig. 3 Left vertebral angiogram on Day 15 demonstrating the irregular lumen of the posterior cerebral artery caused by vasospasm (arrows) and an aneurysm-like shadow (arrowhead).

(Fig. 2). Left vertebral angiography detected the same shadow. Repeat left vertebral angiography on Day 15 revealed irregular lumen of the posterior cerebral artery (PCA) and an aneurysm-like shadow (Fig. 3). Left carotid angiography showed no aneurysm. Selective angiography performed on Day 28 using a microcatheter technique disclosed two medial PChAs that arose from the ambient segment of the left PCA. One medial PChA incorporated an aneurysm on the cisternal segment and then ran peripherally to supply the plexus in the roof of the third ventricle. The other medial PChA mainly seemed to supply the pineal body, tegmentum of the midbrain, and posterior border of the thalamus. A lateral PChA arose from the parieto-occipital artery that supplied the plexus of the atrium and the body of the lateral ventricle (Fig. 4).

The patient underwent open surgery following the left zygomatic approach on Day 29. Proximal clipping of the parent artery was performed. A purple aneurysm with no neck was found. Postoperative selective angiography revealed that one medial PChA was closed by the clip, but the other medial PChA was preserved and supplied the same region irrigated preoperatively, and the plexus in the roof of the third ventricle was opacified via the anastomosed circulation. The patient was discharged without neurological deficits or compromise of higher brain functions.

\section{Discussion}

One previous case of medial PChA aneurysm associated with moyamoya disease was located at the distal portion and manifested as thalamic hemorrhage and ventricular penetration. ${ }^{4}$ Most previously reported cases (10 of 11) of PChA aneurysm were located at the distal portion of the PChA and presented with initial findings of intracerebral or subarachnoid hemorrhage. ${ }^{2-5,8,9,12)}$

Asymmetrical intraventricular hemorrhage most pronounced within the atrium of the lateral ventricle on CT is one of the characteristics of aneurysms located at the distal portion of the lateral PChA. ${ }^{12)}$ In our patient, the aneurysm arose at the proximal portion (cisternal segment) of the medial PChA, which may have been one of the reasons why it was so difficult to locate precisely. Subarachnoid hematoma similar to that seen with IC-PComA or basilar tip aneurysm, lack of ventricular hemorrhage, and especially spasm of the PCA and the PComA made it difficult to locate the parent artery and the aneurysm. However, spasm predominantly affecting the PCA and PComA may be one of the characteristics of this unusual aneurysm.

The microcatheter technique is remarkably useful for determining the site, shape, and parent artery of the aneurysm. ${ }^{5,12)}$ In our case, only the microcatheter technique could differentiate the medial PChA from the lateral PChA or PCA and could identify the two medial PChAs that arose from the ambient segment of PCA and supplied different areas.

Aneurysms can be treated by endovascular surgery or open surgery. Four of the 11 previous cases 


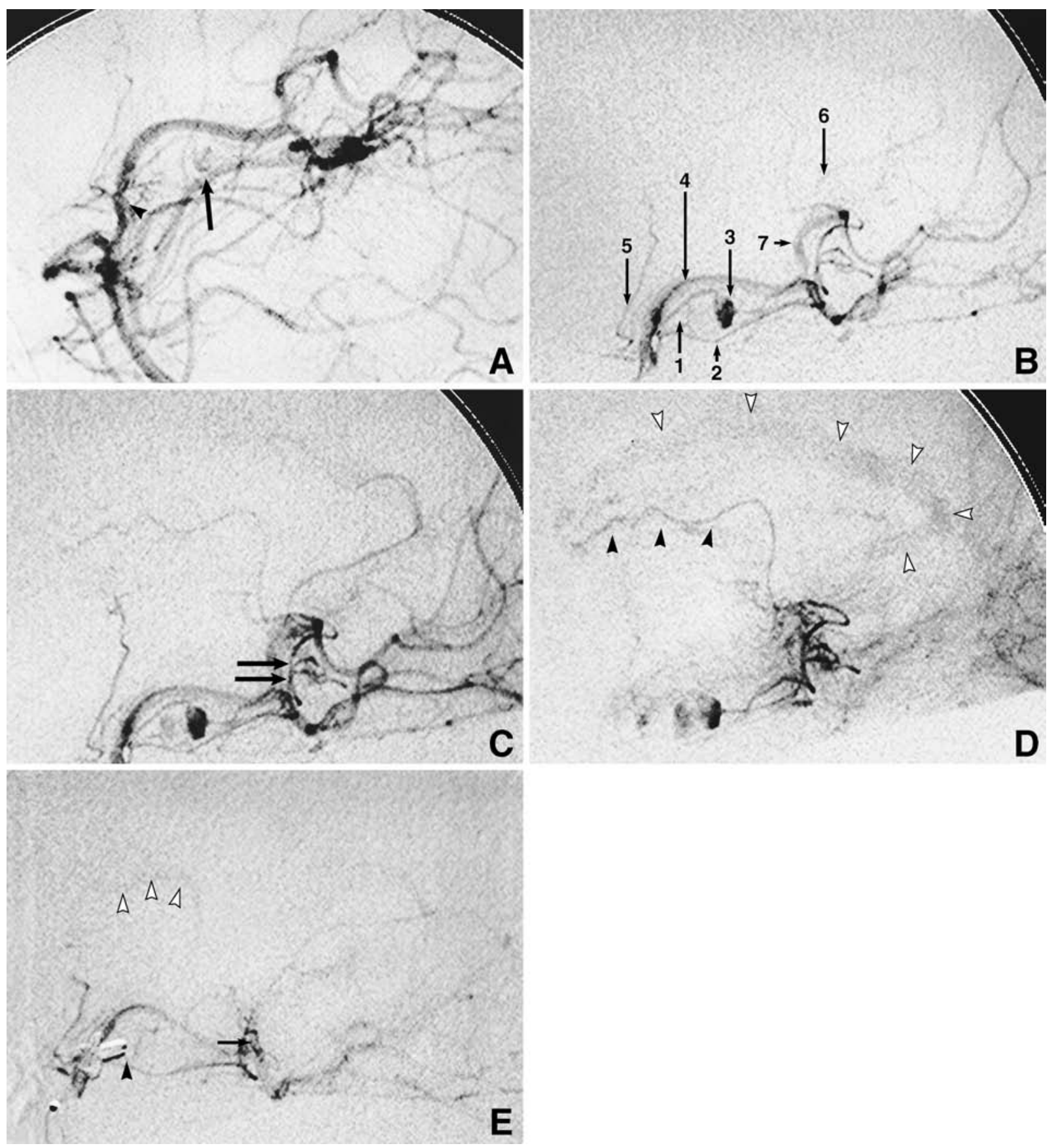

Fig. 4 A: Preoperative left vertebral angiogram showing an aneurysm-like shadow (arrow). The tip of the microcatheter is positioned at the $P_{1}-P_{2}$ junction (arrowhead). B-D: Selective angiograms from the same angle revealing two medial posterior choroidal arteries (PChAs) (1 and 2) that arose from the ambient segment of posterior cerebral artery (4). The aneurysm (3) arose at the cisternal segment of one medial PChA, which ran peripherally to supply the plexus in the roof of the third ventricle (solid arrowheads). The other medial PChA mainly supplied the pineal body, tegmentum of the midbrain, and posterior border of the thalamus (double arrow). The thalamoperforating arteries (5) arose at the end of $P_{1}$ segment. The lateral PChA (6) arose from parieto-occipital artery (7) and supplied the plexus of the atrium and body of the lateral ventricle (open arrowheads). E: Postoperative selective angiogram showing proximal clipping of the parent artery (solid arrowhead) and the preserved medial PChA supplying the same region as preoperatively (arrow). The plexus in the roof of the third ventricle was opacified through the anastomosed circulation (open arrowheads). 
were treated by open or endovascular surgery. The parent artery was trapped and the aneurysm excised via the left parieto-occipital approach, ${ }^{2)}$ whereas endovascular surgery was performed to occlude both the parent artery and the aneurysm soon after identifying the lateral PChA aneurysm. ${ }^{5,12)}$ Endovascular coiling with parent artery preservation is generally preferable to occlusion of the parent vessel, but the small size of both the parent artery and the aneurysm made this unfeasible. ${ }^{12)}$ The procedure was functionally equivalent to the open surgical trapping of the aneurysm and parent vessel occlusion. We attempted the same procedure but the catheter could not reach the optimal position because of the small size of the medial PChA. The following day, open surgery was performed via the zygomatic approach, which provided good exposure of the proximal PCA, medial PChA, and the aneurysm. We think that if the aneurysm is on the proximal portion of the lateral or medial PChA and the parent artery is small, open surgery should be performed.

The medial PChA supplies the choroid plexus in the roof of the third ventricle and the lateral ventricle, and also branches to the thalamus, pineal body, cerebral peduncle, and tegmentum of the midbrain. ${ }^{1,6,7,10,13)}$ There are two main neurological features of medial PChA territory infarction, eye movement disorders and sensorimotor dysfunction. ${ }^{7)}$ Postoperatively, our patient exhibited no neurological deficits or compromise of higher brain functions. Our patient had two medial PChAs, the one that was trapped supplied mainly the plexus in the roof of the third ventricle whereas the one that was preserved seemed to supply the neural structures such as the pineal body, thalamus, and tegmentum of the midbrain. In addition, there were rich anastomoses between the choroidal branches of the ICA and PCA. Postoperative angiography revealed that the occluded region, the plexus in the roof of the third ventricle, was opacified via these anastomoses. The blood supply to a segment of the choroid plexus comes not only from the choroidal arteries arising on the ipsilateral side, but also from the contralateral lateral PChA, medial PChA, and anterior choroidal artery. ${ }^{1,6,7,10,13)}$ Therefore, provocative functional testing of an alert patient should be performed before surgery, especially if only one medial PChA is present or medial PChA to be trapped seems to supply those neural structures.

\section{References}

1) Fujii K, Lenkey C, Rhoton AL Jr: Microsurgical anatomy of the choroidal arteries: Lateral and third ventricles. J Neurosurg 52: 165-188, 1980

2) Hamada J, Hashimoto N, Tsukahara T: Moyamoya disease with repeated intraventricular hemorrhage due to aneurysm rupture. J Neurosurg 80: 328-331, 1994

3) Kodama N, Suzuki J: Moyamoya disease associated with aneurysm. J Neurosurg 48: 565-569, 1978

4) Kwak R, Yamamoto N, Ito S, Kadoya S: [A case of moyamoya disease associated with a peripheral artery aneurysm of the thalamus]. No Shinkei Geka 12: 1419-1423, 1984 (Jpn, with Eng abstract)

5) Maekawa $M$, Nemoto $S$, Awaya $S$, Teramoto A: [Moyamoya disease with intraventricular hemorrhage due to rupture of lateral posterior choroidal artery aneurysm: Case report]. No Shinkei Geka 27: 1047-1051, 1999 (Jpn, with Eng abstract)

6) Margolis MT, Newton TH, Hoyt WF: The posterior cerebral artery. II. Gross and roentgenographic anatomy, in Newton TH, Potts DG (eds): Radiology of the Skull and Brain, vol II, book 2. St Louis, CV Mosby, 1974, pp 1551-1579

7) Neau JP, Bogousslavsky J: The syndrome of posterior choroidal artery territory infarction. Ann Neurol 39: 779-788, 1996

8) Niiro M, Awa H, Kobayashi E, Mihara T, Asakura T: [Cerebral arteriovenous malformation co-existing with a cerebral aneurysm in the territory of the posterior choroidal artery: A case report with reference to considerations of occurrence]. No Shinkei Geka 8: 659-665, 1980 (Jpn, with Eng abstract)

9) Sayama I, Fukusawa H, Yasui N, Suzuki A: [Angiographical extravasation in the intracranial hemorrhage due to cerebrovascular moyamoya disease: Autopsy study]. No To Shinkei 36: 325-331, 1984 (Jpn)

10) Vinace FC, Lopez F, Dujovny M: Microsurgical anatomy of the posterior choroidal arteries. Neurol Res 17: 334-344, 1999

11) Waga $S$, Tochio $H$ : Intracranial aneurysm associated with moyamoya disease in childhood. Surg Neurol 23: 237-243, 1985

12) Weigele JB, Chaloupka JC, Lesley WS, Mangla S, Hitchon PW, VanGilder JC, Adams HP Jr: Peripheral aneurysm of the lateral posterior choroidal artery: Clinical presentation and endovascular treatment: Report of two cases. Neurosurgery 50: 392-396, 2002

13) Zeal AA, Rhoton AL Jr: Microsurgical anatomy of the posterior cerebral artery. J Neurosurg 48: 534-559, 1978

Address reprint requests to: T. Ohta, M.D., Department of Neurosurgery, Ushioda General Hospital, 1-6-20 Yako, Tsurumi-ku, Yokohama, Kanagawa 230-0001, Japan. e-mail: otauma@jcom.home.ne.jp 